\title{
SIGNIFICADOS DE PLANOS DE SAÚDE PARA CONSUMIDORES DE BAIXA RENDA
}

\section{MEANINGS OF HEALTH PLANS FOR LOW INCOME CONSUMERS}

\section{Luiz Felipe Feltrim Julio}

Departamento de Administração da PUC-Rio

Mestre em Administração de Empresas

Rio de Janeiro, RJ, Brasil

Email: luizfelipe.feltrim@gmail.com

\section{Marcus Wilcox Hemais}

Departamento de Administração da PUC-Rio

Professor Assistente de Marketing

Rio de Janeiro, RJ, Brasil

Email: marcus.hemais@iag.puc-rio.br

\section{RESUMO}

A partir dos anos 2000, cresceu o número de consumidores de baixa renda com planos de saúde. Para esse público, além do acesso a hospitais, clínicas e médicos privados, tais planos apresentam significados de consumo que perpassam seus benefícios funcionais. Todavia, o entendimento desses significados ainda é pouco explorado em marketing. O presente estudo busca, portanto, analisar os significados associados por consumidores de baixa renda a planos de saúde. Para isso, foram realizadas 18 entrevistas em profundidade com esses consumidores que possuem ou possuíram tais planos. É possível perceber que o acesso a planos de saúde causa melhora na qualidade de vida desses consumidores, embora exista uma fragilidade da posse desse serviço, por ser oferecido como um benefício a empregados. Além disso, o plano lhes oferece um sentimento de dignidade. Conclui-se que, para consumidores de baixa renda, planos de saúde apresentam significados de inclusão social e maior aprendizado sobre como ser um consumidor.

Palavras-chave: Plano de saúde. Consumidor de baixa renda. Cultura e consumo. Significados.

\section{ABSTRACT}

Since the 2000s, the number of low-income consumers with health plans has grown. For this public, beside the access to private hospitals, clinics and doctors, health plans present consumption meaning that go beyond its functional benefits. However, the understanding of such meanings is still unexplored in marketing. The present study analyzes the meanings associated by low income consumers to health plans. For this, 18 in-depth interviews were conducted with these consumers that have or have had such plans. It is possible to notice that health plans are perceived as causing improvements in the quality of life of low-income consumers, despite the fragility in the possession of such service, since it is offered as a benefit to workers, by companies. Also, health plans offer a feeling of dignity to these consumers. In conclusion, for low income consumers, health plans represent meaning of social inclusion and better learning of how to be a consumer.

Keywords: Health plan. Low income consumer. Culture and consumption. Meanings.

Data de submissão: 19 de setembro de 2017.

Data de aprovação: 29 de outubro de 2019. 


\section{INTRODUÇÃO}

De acordo com dados da Agência Nacional de Saúde Suplementar (ANS) (AGÊNCIA NACIONAL DE SAÚDE SUPLEMENTAR, 2017), o número de cidadãos que tem algum tipo de cobertura privada para despesas de saúde vem aumentando nos últimos anos. No final de 2005, a quantidade de participantes era de 35,4 milhões de beneficiários. Em dezembro de 2018, esse número já alcançava 47,2 milhões de beneficiários. A grande maioria desses usuários do serviço, cerca de 32 milhões, participa de planos coletivos empresariais, e o restante de planos individuais, familiares ou coletivos por adesão, sendo estes formados por sindicatos e associações. Apesar de tamanho crescimento em 10 anos, verificouse que, desde 2014, houve uma diminuição da base de beneficiários, atribuída à desaceleração econômica que o Brasil tem passado. Nesses últimos anos, mais de 2,5 milhões de brasileiros deixaram de possuir planos de saúde (AGÊNCIA NACIONAL DE SAÚDE SUPLEMENTAR, 2017).

Tanto nos momentos de crescimento, quanto naqueles de retração da indústria de planos de saúde, a presença de consumidores de baixa renda na compra e na perda desse serviço é visível. Antes dos efeitos da crise, por exemplo, estima-se que 4,4 milhões de brasileiros da classe D eram proprietários de um plano de saúde (CASADO; SATO, 2012). Por outro lado, esses indivíduos são os que mais perderam acesso ao serviço em questão (ELIAS, 2016), tendo que voltar a utilizar o Sistema Único de Saúde (SUS). Esse cenário de perda é perverso para consumidores de baixa renda porque, mais do que uma alternativa ao SUS, planos de saúde apresentam significados de consumo maiores do que somente a facilidade de acesso a médicos, clínicas e hospitais da rede privada, que ajudam a explicar o motivo da grande estima desse público a tal serviço (ALCOFORADO, 2007; BARONE, 2007). Não poder utilizar mais tais planos, portanto, representa a esses indivíduos um retrocesso em esferas do consumo além das de cunho funcional.

A posse de um plano de saúde representa mais do que somente acesso a estruturas médicas; está relacionado a um contexto social maior, de responsabilidade tanto de governos, quanto de sociedades, que tem na manutenção da saúde de um indivíduo a garantia de incremento na sua qualidade de vida (BUSS, 2000). Lima-Costa (2004) mostra como essa relação ocorre ao apontar que consumidores filiados a planos de saúde possuem estilos de vida mais saudáveis. Em seu estudo, a autora revela que esses indivíduos, em comparação àqueles que somente utilizam o SUS, fumam menos, consomem menos bebidas alcóolicas, praticam mais exercícios e consomem com mais frequência porções diárias de frutas, verduras ou legumes frescos. Além disso, fazem uso com mais frequência de serviços preventivos, tais como exames de pressão arterial, colesterol, mamografia, entre outros. A possibilidade de seguir uma vida saudável por meio de planos de saúde, portanto, é vista como um caminho para a população alcançar bem-estar, felicidade, amor, prazer, realização pessoal, além de auxiliar na satisfação de necessidades básicas e de necessidades criadas pelo grau de desenvolvimento econômico e social de determinada sociedade (MINAYO; HATZ; BUSS, 2000).

É possível perceber, então, que há diversos ganhos funcionais em possuir planos de saúde, tanto para o indivíduo, quanto para a sociedade. Todavia, junto a esses, também se fazem presentes outros tantos aspectos simbólicos relacionados à posse desse tipo de serviço. Pela ótica interpretativista de Cultura e Consumo ( $\mathrm{CeC})$, consumidores escolhem determinados objetos de consumo em razão dos significados que carregam e pela forma como são interpretados por um grupo ao qual desejam pertencer (ARNOULD; THOMPSON, 2005; KOZINETS, 2001). Diferentes estudos ilustram essa perspectiva ao detalhar os simbolismos que consumidores atribuem a diversos bens e serviços, tais como automóveis (RAMALHO; AYROSA, 2009), produtos de beleza (MOREL; MACEDO; SETTE; REZENDE, 2016), shopping centers (MACLAREN; BROWN, 2005), entre outros. Todavia, o entendimento de tais significados associados a planos de saúde ainda é pouco explorado na literatura de marketing. 
Embora estudos em CeC sejam majoritariamente relacionados aos significados associados por consumidores de mais alta renda a diferentes bens (CASOTTI; SUAREZ, 2015), algumas pesquisas no Brasil têm utilizado essa perspectiva para analisar o comportamento de consumidores de baixa renda e os simbolismos que percebem em diferentes produtos e serviços (PINTO, 2013; ROCHA; ROCHA, 2012). Dado que a relação desse público com o consumo é tida como distinta daquela de seus pares mais abastados (CHAUVEL, 2000; SANTO; HEMAIS, 2017), torna-se importante analisar sua visão sobre esse fenômeno, em particular a sua relação com planos de saúde, visto que faltam estudos que se dediquem a analisar essa questão.

Dada essa lacuna na literatura de marketing, o presente estudo busca analisar quais são os significados associados por consumidores de baixa renda a planos de saúde. Para alcançar esse objetivo, foi realizada uma pesquisa interpretativista, por meio de entrevistas em profundidade com 18 consumidores do grupo em questão, que possuíam ou já possuíram planos de saúde. Espera-se, a partir dos resultados do estudo, contribuir com mais conhecimento para a literatura da área ao adotar uma perspectiva de $\mathrm{CeC}$ para analisar uma relação de consumo ainda pouco explorada, ajudando a entender um pouco mais sobre esse determinado público consumidor e esse serviço em particular e como a qualidade de vida do primeiro é impactada pela posse do segundo.

O restante do artigo é dividido em mais quatro itens. O segundo discute o referencial teórico do estudo, em particular os significados de consumo para consumidores de baixa renda. $O$ terceiro discute a metodologia adotada no presente estudo. O quarto apresenta a análise dos dados. Por fim, no quinto item, são feitas as considerações finais.

\section{SIGNIFICADOS DE CONSUMO PARA CONSUMIDORES DE BAIXA RENDA}

Estudos sobre cultura e consumo têm sido amplamente realizados nas últimas décadas dentro da área de comportamento do consumidor (DOUGLAS; ISHERWOOD, 2009; MCCRACKEN, 2003). Tal linha de pesquisa se baseia em uma perspectiva interdisciplinar, que analisa os aspectos culturais envolvidos no consumo, gerando resultados empiricamente fundamentados e inovações teóricas relevantes (ARNOULD; THOMPSON, 2005). Por essa perspectiva, consumidores tomam emprestado o que cada bem ou serviço representa socialmente e, com essas representações, constroem significados com suas experiências pessoais (BELK, 1988) ou de determinados grupos (MCCRACKEN, 2003). O consumo, portanto, não se restringe a aspectos funcionais; na verdade, ele se dá pela escolha dos significados inseridos em determinados objetos, interpretados de certa forma por um grupo ao qual o indivíduo quer pertencer (KOZINETS, 2001).

Embora estudos sobre $\mathrm{CeC}$ tenham se concentrado em analisar os simbolismos pela perspectiva de consumidores de classes sociais mais afluentes (CASOTTI; SUAREZ, 2015), todos possuem o desejo de consumir e buscam a felicidade por meio do consumo (BELK; GER; ASKERGAARD, 2003), independentemente de seu status social. Todavia, são poucas as pesquisas relacionadas a essa perspectiva que buscam analisar os simbolismos associados por consumidores de baixa renda a produtos e serviços, o que limita a capacidade explanatória dessa linha teórica.

Essa falta de maior conhecimento sobre as associações simbólicas de consumidores de baixa renda ao consumo pode ser explicada pelo fato de a área de marketing, tanto no Brasil, quanto no exterior, pouco atentava a esse público há até pouco tempo (PRAHALAD, 2006; ROCHA, 2009). Até meados dos anos 1990, o empresariado e o meio acadêmico brasileiros tinham maiores preocupações em atender consumidores de mais alta renda, por acreditar que seriam eles os únicos com poder de consumo para adquirir bens que não fossem necessariamente os de primeira necessidade (BARROS, 2006). 
Esse quadro começou a mudar a partir do advento do Plano Real, quando houve maior controle da inflação, mais programas de transferência de renda, queda do desemprego com a formalização do trabalho, retomada dos investimentos públicos e a expansão do crédito (SOUZA; PIERUCCINI; KACHUBA, 2015), que culminaram em um maior poder de consumo do segmento de baixa renda. Consequentemente, passaram a surgir mais preocupações empresariais em entender esse "novo" consumidor e pesquisas acadêmicas que tentaram desvendar seu comportamento, especialmente depois que Prahalad passou a discutir o tema (PRAHALAD; HAMMOND, 2002; PRAHALAD; HART, 2002).

Diversas pesquisas sobre consumidores de baixa renda no Brasil têm se dedicado a desvendar quem é esse indivíduo e qual é a sua relação com o consumo, a partir de uma perspectiva interpretativista. Barros (2006), por exemplo, evidenciou que esses consumidores mostram grande desejo de participar dos benefícios da sociedade de consumo, de modo que, ao consumir, sentem que estão se distinguindo de outros indivíduos da mesma classe social, aproximando-se do "mundo dos ricos".

Assim como seus pares de mais alta renda, consumidores de baixa renda também percebem que bens de consumo possuem significados e que sua posse resulta em uma hierarquização da sociedade, de forma a separar os que têm ("elite dos pobres") dos que não têm ("pobres-pobres") (CASTILHOS; ROSSI, 2009). Mesmo em regiões menos favorecidas, há indivíduos que se destacam de seus pares, sendo considerados a elite local, pois consomem bens e serviços que seus pares mais próximos não possuem acesso (ROCHA, 2009). Apesar de possuir meios para sair desses locais e residir em regiões mais valorizadas, essa elite não deseja se mudar, pois, para ela, é mais importante manter seu status (YACCOUB, 2011).

Mattoso e Rocha (2008) mostram o quanto o consumo de crédito serve a essa finalidade de diferenciação entre consumidores de baixa renda. Segundo as autoras, consumidores que possuem um ou mais cartões de crédito são vistos na comunidade onde moram como destacados. Isso ocorre porque, além de maior poder de consumo, esses indivíduos são diferenciados o suficiente para que empresas financeiras thes ofereçam mais acesso a crédito, pois são dignos de confiança e pagam suas dívidas. Por outro lado, quando consumidores de baixa renda perdem acesso a crédito e têm seus nomes "sujos", colocados em listas de maus pagadores, sentem-se inferiorizados perante seus pares, como se perdessem sua identidade de consumidor (MATTOSO; ROCHA, 2008), já que dificilmente conseguem manter condições de realizar compras mais expressivas, de maior valor (PONCHIO; ARANHA, 2009).

A impossibilidade de consumidores de baixa renda firmarem sua identidade de consumidor reforça seus pensamentos de que são "cidadãos de segunda classe", o que, consequentemente, perpetua seus sentimentos de baixa autoestima (BARKI; PARENTE, 2010). Esse estado mental se agrava ainda mais quando se deparam com a precarização de serviços públicos, tais como segurança, educação, saúde e saneamento básico, sem que possam mudar, por conta própria, essa situação. A alternativa para elevar sua autoestima é, portanto, consumir bens e serviços de natureza mais supérflua, mesmo que suas necessidades básicas ainda não tenham sido completamente atendidas (LIVRAMENTO; HORMEYLL; PESSÔA, 2012).

O consumo de bens e serviços de marcas mais conhecidas e mais conceituadas se torna, então, uma forma de consumo comum a consumidores de baixa renda (CHAUVEL; MATTOS, 2008). Diferentemente de seus pares de alta renda, que têm tais bens como parte integrante de suas vidas, esses indivíduos com menos recursos veem nesses um bem aspiracional, que os permite ser incluídos na sociedade, ajudando a elevar sua autoestima. Além do aspecto aspiracional, o consumo de bens "de marca" também serve como uma garantia a esses consumidores de que o dinheiro investido trará o retorno esperado, pois o produto cumpre os benefícios que promete (BARROS; ROCHA, 2009), evitando, assim, que se sintam enganados (CHAUVEL, 2000). 
Os estudos apresentados aqui mostram os diversos significados de consumo e como consumidores de baixa renda os associam ao consumo de bens e serviços. Esse entendimento serve, portanto, para ajudar o presente estudo a analisar quais são os significados atribuídos por esses consumidores a planos de saúde. Em continuação à busca por alcançar esse objetivo, a metodologia adotada na pesquisa de campo é descrita.

\section{METODOLOGIA}

Dado que a presente pesquisa busca compreender significados associados por consumidores de baixa renda a planos de saúde, entende-se que um estudo interpretativo seja mais adequado para esse fim (CRESWELL, 2010). Outros estudos no Brasil vêm utilizando a visão interpretativista para pesquisar significados de consumo associados por consumidores de baixa renda a produtos e serviços (PINTO, 2013; ROCHA; ROCHA, 2012), reforçando a adequação da escolha feita aqui.

Os participantes da presente pesquisa foram consumidores de baixa renda, que possuíam ou já possuíram planos de saúde (nesses casos, os entrevistados deixaram de possuir seus planos pouco antes das entrevistas, portanto sabiam discutir detalhadamente os significados associados ao serviço). Dado que o foco do estudo era em analisar o comportamento de consumidores com esse perfil, foi perguntado a cada um dos participantes da pesquisa se possuíam ou já tiveram um plano de saúde e qual era a sua renda familiar mensal, entre outras perguntas de cunho demográfico. Como tais perguntas eram feitas somente ao final das entrevistas, aquelas cujos entrevistados não atendiam esses critérios foram descartadas. Ao todo, foram entrevistados 18 consumidores com o perfil desejado, sendo que 16 possuíam um plano e dois não mais o possuíam. Do grupo de entrevistados que possuía um plano, 15 se diziam titulares e somente um indicou ser dependente. Entre os entrevistados, oito são homens e 10 são mulheres, com idades entre 18 e 89 anos, e nível de instrução que varia desde ensino fundamental incompleto a ensino superior completo. Quanto ao seu estado civil, foram entrevistados consumidores que se diziam casados, solteiros, divorciados e viúvos. Um grupo de entrevistados encontra-se empregado, enquanto outro está desempregado ou aposentado.

Embora ainda não exista consenso no Brasil sobre quais consumidores são do grupo de baixa renda (NOGAMI; VIEIRA; MEDEIROS, 2012), considerou-se que esses seriam aqueles pertencentes às classes D e E (assim como os estudos de Neri (2011), Levrini e Poletti (2016) e Mattoso e Rocha (2008)), segundo classificação do IBGE, pela qual consumidores da classe D possuem renda familiar mensal, em 2016, entre $R \$ 1.760,01$ e $R \$ 3.720,00$ e aqueles da classe E estão abaixo de $R \$ 1.760,01$. Segundo essa classificação, dos 18 entrevistados da presente pesquisa, oito são da classe D e 10 são da classe $E$.

A coleta de dados ocorreu por meio de entrevistas em profundidade. Para guiar as entrevistas, foi elaborado um roteiro, com perguntas baseadas no referencial teórico. O roteiro foi testado, a fim de encontrar inconsistências ou perguntas de difícil entendimento aos entrevistados, seguindo recomendações de Casotti, Suarez e Dileza (2009). Após uma rodada de entrevistas teste com três consumidores do grupo pesquisado, percebeu-se que havia perguntas redundantes e algumas palavras incompreensíveis aos entrevistados, levando os pesquisadores a realizar modificações no roteiro. Após tais modificações, mais duas entrevistas teste foram realizadas, não sendo percebidas mais dificuldades de compreensão. 
As entrevistas foram realizadas em diferentes locais. Inicialmente, a coleta de dados se deu em uma universidade particular, onde os pesquisadores tinham acesso a funcionários, cujo perfil se enquadrava naquele desejado. Em um segundo momento, as entrevistas foram realizadas em unidades de atendimento de planos de saúde e em hospitais privados, após os pesquisadores obterem autorização com as operadoras de planos de saúde que os gerenciavam.

A fim de analisar os dados coletados, os pesquisadores seguiram duas etapas. Na primeira, as transcrições das entrevistas foram codificadas, com o objetivo de organizar os dados (CRESWELL, 2010). Esse procedimento também permitiu que se chegasse à saturação dos dados, quando novos códigos não mais surgiam durante a codificação das entrevistas (GUEST; BUNCE; JOHNSON, 2006). Ao todo, foram cadastrados 81 códigos, atribuídos a determinados trechos do relato dos entrevistados baseados nos principais conceitos descritos na revisão de literatura (CARSON et al., 2005) ou a partir de particularidades encontradas nas entrevistas (RUBIN; RUBIN, 2005).

$\mathrm{Na}$ segunda etapa, as informações codificadas foram refinadas, a fim de se chegar às categorias de análise do estudo. Este refinamento se deu por um processo de comparação dos códigos, a fim de encontrar diferenças e semelhanças nos incidentes relatados (ANFARA; BROWN; MANGIONE, 2002; GUMMESSON, 2005; SPIGGLE, 1994), agrupando-os em categorias de análise. Dessa forma, chegou-se a três categorias de análise, sendo a categoria intitulada de "Melhora de vida causada pelo acesso a planos de saúde" composta por 29 códigos, enquanto que as categorias "A fragilidade da posse do plano de saúde" e "Dignidade com plano de saúde, desrespeito no SUS" formadas por 25 e 27 códigos, respectivamente.

\section{ANÁLISE DOS DADOS}

O presente tópico apresenta a análise dos dados, sendo dividido em três partes. A primeira parte aborda como os entrevistados acreditam que o acesso a planos de saúde os traz uma melhora em sua qualidade de vida. Na segunda parte, é discutida a fragilidade do acesso a planos de saúde. Na terceira parte, é apresentada discussão sobre como planos de saúde tratam dignamente consumidores de baixa renda, enquanto o SUS é tido como desrespeitoso.

\section{Melhora de vida causada pelo acesso a planos de saúde}

A visão dos entrevistados sobre seus planos de saúde é de que, de uma forma geral, o serviço lhes trouxe uma melhora em sua qualidade de vida. Possuir tais planos é associado a "segurança" e "amparo", "um certo alívio" em saber que há um "serviço de qualidade" ao alcance. Entre os entrevistados sem um plano, essa visão parece ser ainda mais forte, porém no sentido de uma piora em sua qualidade de vida, o que se alinha com a visão de Belk (1988) sobre os significados de consumo se tornarem mais claros quando há uma subtração do bem. Ambas as consumidoras nessa situação alegam se sentir "desassistidas" e "preocupadas quanto à saúde", pois, se vierem a adoecer, somente poderão contar com a rede pública. Antes, quando possuíam um plano, a vida "estava tranquila", em referência à "paz de espírito" que o acesso a serviços privados de saúde as proporcionava. Alguns entrevistados relataram que essa melhora de vida estava relacionada ao acesso a "boas" redes de clínicas, hospitais e médicos, conforme Marcos (19 anos, repógrafo) relata: "me senti melhor, como se a minha saúde estivesse melhorando". 
Essa perspectiva sobre melhora na qualidade de vida de consumidores de baixa renda por meio do consumo já foi discutida por Prahalad e colegas (PRAHALAD; HAMMOND, 2002; PRAHALAD; HART, 2002). Porém, sua visão relaciona a melhora ao acesso a funcionalidades que, antes, eram desconhecidas por esse público. No caso da presente pesquisa, a melhora referida está mais próxima à visão encontrada por outros autores (BARROS; ROCHA, 2009; CASTILHOS; ROSSI, 2009), que sugerem que o consumo traz efeitos sociais benéficos sobre indivíduos, que passam a sentir felicidade por consumir algo que thes insere em um grupo social. O consumo, portanto, ajuda a formar um senso de pertencimento no consumidor, fazendo com que sua identidade chegue mais perto àquela de um grupo ao qual deseja pertencer (ARNOULD; THOMPSON, 2005; KOZINETS, 2001).

Por essa lógica, o oposto também ocorre, pois consumidores de baixa renda apresentam sentimentos de piora em sua qualidade de vida após perderem acesso a planos de saúde e outros bens e serviços. Mattoso e Rocha (2008), por exemplo, indicam um sentimento de exclusão entre seus entrevistados quando falam sobre terem seu "nome sujo" e, por isso, estarem impossibilitados de conseguir crédito financeiro. Para as autoras, os sentimentos negativos agudos em relação a essa situação refletem, inclusive, na identidade do consumidor, que muda por não mais poder consumir aquilo que, outrora, estava ao seu dispor.

Possuir um plano de saúde era uma realidade distante para diversos entrevistados, especialmente por não ser um serviço comum em seu círculo social, por ser "uma coisa de rico". Possuir algo que somente "os ricos" tinham acesso, portanto, é motivo de orgulho, o que pode ser explicado por consumidores de baixa renda aspirarem ao estilo de vida de indivíduos das classes sociais mais elevadas, por serem consumidores que sabem se defender contra empresas e possuem acesso a mais informações e melhores produtos e serviços (CHAUVEL, 2000). Leandro (18 anos, assistente administrativo), por exemplo, fala sobre seu orgulho em possuir um plano de saúde da seguinte forma: "Tenho a cabeça erguida, por eu ter um plano e condições de pagar o meu próprio". Além de orgulho, a partir da posse do plano de saúde também leva a uma sensação de inclusão social, conforme exposto a seguir:

O plano de saúde era uma coisa que nunca tive acesso. Só ouvia alguém falando. Era uma realidade distante da minha. Quando foi me oferecido na época, eu aceitei de cara, logo. Você fica mais calmo, pois se não conseguir ir no [hospital] público, tem o plano. Me sinto satisfeito em saber que tenho essa opção (Fernando, 33 anos, auxiliar administrativo).

A posse de um plano de saúde tem tamanha importância para alguns consumidores que chega a ser comentada com amigos, vizinhos e familiares, que, por sua vez, aplaudem o entrevistado por seu consumo, conforme relatam Raquel (40 anos, oficial de limpeza): "Minha família sabe (que a entrevistada possui um plano de saúde), minha rua toda também sabe. Falo que o plano de saúde é muito bom" e Marcos (19 anos, repógrafo): "Sabem (que o entrevistado possui um plano de saúde), eu falei. Quando cheguei em casa, eu avisei, porque na minha família ninguém tem essas coisas".

Diversos outros estudos sobre consumidores de baixa renda no Brasil discutem a questão da inclusão social por meio da posse (BARKI; PARENTE, 2010; MATTOSO; ROCHA, 2008). Em geral, tais estudos mostram que, mais do que o tipo de profissão exercida por esses indivíduos, é a posse de bens e serviços que thes dá maior sentimento de inclusão na sociedade. Dado que as profissões que exercem são consideradas de menos prestígio, por sua natureza mais manual do que intelectual, é por meio do consumo que sentem estar em pé de igualdade com consumidores de classes sociais mais elevadas, pois se igualam no momento que consomem o mesmo produto ou serviço (CASTILHOS; ROSSI, 2009). 
Vale ressaltar que, por mais importante que o plano de saúde pareça ser para a melhora na qualidade de vida dos entrevistados, não é visto como uma prioridade em seus gastos, já que alguns relatos mostram uma preferência por consumir outros bens e serviços considerados supérfluos, tais como um jantar em um restaurante, um celular mais caro, um carro mais novo ou uma viagem. Nesse caso, parece que a perda do plano de saúde não chega a ser tão drástica quanto a perda do acesso ao crédito discutida por Mattoso e Rocha (2008), conforme ilustra o relato a seguir:

A vida está difícil para a gente, nesse momento, pra fazer qualquer tipo de redução pra poder começar a pagar um plano de saúde novamente... Meu esposo tem carro, moramos em uma casa modesta, mas eu não sei se deixaria de ter algumas coisas para poder pagar o plano de saúde. Como pobre, eu vivo decentemente (Jaqueline, 36 anos, desempregada).

Uma explicação para essa forma de pensamento pelos entrevistados pode ser porque o consumo desses produtos e serviços citados traz um prazer instantâneo, diferentemente de um plano de saúde, que é usado esporadicamente e, em geral, para situações que o consumidor não deseja estar vivenciando. "Não é sempre que a gente precisa (do plano de saúde). Não é todo mês. A gente usa quando precisa, não é sempre... Pode ser um dia e só usar de novo três meses depois (Marcos, 19 anos, repógrafo). Além disso, abrir mão de bens e serviços, tais como um carro ou uma viagem, pode ser entendido como uma redução no padrão de vida desses consumidores, algo difícil de fazer, especialmente por considerarem suas vidas cheias de restrições ("a vida está difícil para a gente"). Após a expansão econômica e a recuperação do crescimento no Brasil, a partir da década de 2000, consumidores de baixa renda passaram para outro patamar de consumo (SOUZA; PIERUCCINI; KACHUBA, 2015). Voltar aos níveis anteriores, portanto, é difícil por representar um retrocesso, o que faz alguns entrevistados remeterem à ideia de que "pobre tem seu lugar", e que esse não é em clínicas e hospitais particulares oferecidos pelos planos de saúde.

A redução no consumo, para esses consumidores de baixa renda, representa retornar a patamares inferiores na escala hierárquica da sociedade, sem sequer poder se diferenciar de seus pares desse segmento. Em uma sociedade que coloca a riqueza como importante demarcador de status social (MATTOSO; ROCHA, 2008), é natural entender que a despesa com a manutenção de um plano de saúde fique em segundo plano quando comparado a outros bens mais tangíveis, como um celular mais caro ou um jantar em um restaurante.

Consumir um plano de saúde mostra-se, para esses consumidores de baixa renda, uma forma de melhora de qualidade de vida e de diferenciação, uma porta de saída de uma condição de pobre para a de menos pobre, permitindose sair da "invisibilidade" e "se tornar alguém" por possuir algo que poucos outros de seu entorno possuem (ROCHA, 2009). Entretanto, essa condição é entendida pelos entrevistados como algo frágil, pois a posse do plano de saúde está condicionada, em diversos casos, a estar empregado, pois são empresas que proporcionam a eles a possibilidade de consumir tal serviço. 


\section{A fragilidade da posse do plano de saúde}

Os relatos mostram que o principal motivo para os entrevistados possuírem um plano de saúde é por esse ser um benefício concedido pelas empresas nas quais estão empregados. Falar de planos de saúde, portanto, implica em discutir, também, a relação entre consumidores de baixa renda e empresas nas quais trabalham. Na maioria dos casos, os relatos indicam que consumir um plano de saúde é única e exclusivamente possível por esse benefício ser oferecido pela empresa empregadora, conforme ilustrada Patricia (45 anos, desempregada):

Não é todo mundo que tem condições de ter um plano de saúde (...). A maioria das pessoas que tem plano de saúde ou tem condição financeira boa para poderem pagar individual ou tem um emprego onde a empresa oferece.

Diferentemente de um produto que o consumidor compra e, assim, passa a possui-lo, o acesso ao plano de saúde para os entrevistados está intimamente relacionado ao tempo enquanto são empregados de alguma empresa. Consumir um plano de saúde, portanto, não é sinônimo de perpetuidade, pois está condicionada a estar trabalhando. Consequentemente, estar integrado a um grupo ao qual o consumidor deseja pertencer, cujo acesso é facilitado pela posse de bens (ARNOULD; THOMPSON, 2005), também acaba dependendo dessa frágil condição: "Eu demorei um tempo para dizer aos outros que também tinha perdido o plano (além do emprego, após ser demitida)", relata Jessica (25 anos, desempregada). Existe a possibilidade de o consumidor pagar pelo serviço por conta própria, com seus recursos financeiros, mas isso é uma realidade além das condições financeiras dos entrevistados: "Lá em casa tem eu, minha mãe, minha esposa e minhas filhas. Não tem condições de eu pagar o plano sozinho, é muito caro" (Carlos, 49 anos, auxiliar de serviços gerais).

Essa frágil condição faz os entrevistados entenderem que são "quase dependentes" das empresas para terem acesso a planos de saúde, e que a perda do emprego implica não somente na redução da renda familiar, mas também na suspensão do acesso a esse serviço: "Imagina se eu perco o meu emprego; eu perco o meu plano de saúde!", exalta Cleonice (45 anos, auxiliar de serviços administrativos). Quando falam dessa dependência, os entrevistados apresentam sentimentos opostos, pois ao mesmo tempo em que são gratos por terem acesso ao serviço, temem perdê-lo "num piscar de olhos" se a empresa decidir demiti-los. Em alguns casos, inclusive demonstram pouca estima pelo tipo de trabalho que exercem ou a empresa na qual estão empregados, mas alegam que se mantém vinculados a esse emprego porque o "sacrifício" vale o benefício de ter um plano de saúde, conforme ilustra o relato a seguir:

É por isso que eu me mantenho no trabalho, para poder manter meu plano de saúde. É um estímulo para eu poder me manter no trabalho. Conservando meu trabalho, eu sei que conservo meu plano de saúde (Alexandre, 49 anos, Líder de Limpeza).

A fragilidade da situação exposta acaba por afetar a forma como os entrevistados percebem a empresa na qual trabalham. As melhores organizações para se trabalhar são aquelas que concedem planos de saúde a seus funcionários. Indivíduos de baixa renda que trabalham em locais que não oferecem esse benefício, então, estariam em uma posição social inferior, não somente por Ihes faltar acesso ao serviço, mas também porque precisam trabalhar em uma empresa com poucos atrativos empregatícios, conforme relata Raquel (40 anos, oficial de limpeza): "Meus amigos ficaram bobos 
(quando souberam que a entrevistada passaria a ter um plano de saúde), porque nem toda firma oferece plano de saúde. A minha firma ofereceu". Os bons sentimentos associados a planos de saúde, portanto, acabam sendo transferidos às empresas que os oferecem a seus funcionários, como se estivessem ajudando esses indivíduos a formarem suas identidades (BELK, 1988) por meio do consumo de um serviço que dificilmente teriam acesso se não fosse por esse facilitador.

A importância dada à oferta do plano de saúde como um benefício em uma empresa é tamanha que, quando aventada a possibilidade de substituição do plano de saúde por um aumento no salário, em igual montante ao custo do plano, a maioria dos entrevistados relata preferir manter o serviço, conforme relata Deise (46 anos, auxiliar de serviços gerais): "Acho que vale a pena (possuir um plano de saúde), se não, eu ia sofrer lá no SUS, na Clínica da Família". Esse benefício, inclusive, é visto como "essencial" entre os entrevistados na escolha da empresa na qual vão trabalhar e grande motivador para manter o emprego atual. Mesmo se recebessem uma oferta de emprego por outra empresa, não mudariam se não lhes fosse oferecido um plano de saúde:

Não aceitaria (trabalhar em uma empresa que não oferecesse plano de saúde a seus funcionários). Era a primeira coisa que ia perguntar... Tem empresa que agente se machuca lá dentro e é com você mesmo... Eu já trabalhei passando mal, e não fui liberado para ir ao médico. Aqui, não. A gente tem o plano de saúde, tem um médico aqui embaixo, e podemos ser consultados (Renan, 22 anos, ajudante de pedreiro).

O temor dos entrevistados em relação a perder seus planos de saúde, em grande parte, está atrelado à visão de que isso signifique precisarem usar o SUS, um serviço cheio de significados negativos.

\section{Dignidade com plano de saúde, desrespeito no SUS}

Em diversos momentos, os entrevistados comparavam planos de saúde ao serviço público de saúde. Todos os entrevistados indicaram já ter utilizado SUS e, por isso, exaltados positivamente planos de saúde, enquanto o serviço público é visto como "péssimo". É importante ressaltar, entretanto, que os entrevistados, sempre que falavam sobre seus planos de saúde, remetiam a hospitais, clínicas e médicos associados ao plano, como se fossem parte de um mesmo serviço, sem diferenciar a operadora do plano das demais instituições que fazem parte dessa rede. É claro que, sem tal rede, não há um serviço associado a planos de saúde. Mas, o ponto levantado aqui é que em momento algum os entrevistados falavam do plano dissociado dessa rede. Quando falavam de seus planos de saúde e o comparavam com o serviço público de saúde, faziam-no considerando os pontos positivos dos hospitais, clínicas e médicos, e não propriamente das operadoras.

O ponto mais importante para esses consumidores de baixa renda em valorizarem planos de saúde quando comparados ao serviço público de saúde é a ideia de que, com o primeiro, são tratados com dignidade, enquanto que "no público, é descaso, desrespeito total". Em um contexto de privações, com sentimentos de discriminação contra eles (SANTOS; HEMAIS, 2017), poder fugir das agruras que o serviço público Ihes oferece e, ainda, ser bem tratado, parece ser uma dádiva em suas vidas: "O médico do plano privado trata o paciente com dignidade. O médico conversa contigo, bota um aparelhinho, passa um exame para confirmar... faz uma grande diferença no atendimento" (Deise, 46 anos, auxiliar de serviços gerais). 
Quando falam do atendimento recebido em clínicas e hospitais públicos, os entrevistados frequentemente relatam más experiências ("ruim", "um caos", que leva pessoas a "morrer na fila"), tempo excessivo de demora no atendimento e descaso e prepotência dos funcionários e médicos que lhes atendem. Possuir um plano de saúde no Rio de Janeiro é, portanto, "quase uma necessidade", para que possam "fugir" dessa situação precária. Acabam, assim, associando o SUS a algo desrespeitoso, que ignora seus direitos e o fato de serem consumidores e cidadãos que pagam impostos para serem tratados dignamente, conforme ilustram os relatos a seguir:

Tem algumas pessoas ali no (Hospital) Miguel Couto que não tratam a gente bem. Não sei se é por causa do uniforme, não sei. Falei pra moça: "Olha, eu tenho plano de saúde, mas só estou vindo aqui porque estou com a pressão muito alta... o atendimento de vocês é péssimo. Eu tenho plano de saúde e sou muito bem tratada lá." (Raquel, 40 anos, oficial de limpeza).

Você vai no SUS, e muito mal olham na sua cara. O médico do SUS te trata com maior descaso: "você deve estar com isso aqui. Toma esse remédio e vai procurar outro médico" (Deise, 46 anos, auxiliar de serviços gerais).

Devido a suas inúmeras restrições financeiras, é comum que consumidores de baixa renda apresentem baixa autoestima (BARKI; PARENTE, 2010), o que acaba por Ihes trazer sentimentos de exclusão social (LIVRAMENTO; HORMEYLL; PESSÔA, 2012). Quando sentem, portanto, que alguém os está rebaixando ainda mais, reforçando sua marginalização, passam a ter sentimentos de "revolta", especialmente por acreditarem que, em clínicas e hospitais públicos, esse tipo de descaso não deveria ser direcionado a eles, pois, afinal, são "lugares para pobres". Esse sentimento é agravado pela percepção dos entrevistados de que atendentes, técnicos de enfermagem e enfermeiras da rede pública são, também, dos estratos de baixa renda, portanto, deveriam entender as dificuldades que esse público vivencia, e não desrespeitá-lo. Experiências negativas como essas somente alimentam os desejos desses consumidores em participar dos benefícios da sociedade de consumo e estar mais próximo ao "mundo dos ricos" (BARROS, 2006).

Nesse mar de críticas ao serviço público de saúde, há entrevistados que conseguem encontram pontos positivos sobre esse ambiente. Apesar de "frios" e "dar pouca atenção", a qualificação dos médicos de emergências em hospitais públicos é ressaltada: "Nos hospitais públicos, principalmente nas emergências, é onde estão os melhores médicos, porque ali eles pegam cada coisa que no particular não pega" (Patricia, 45 anos, desempregada). Outro fator destacado foi o acesso gratuito a remédios, algo percebido como importante para os entrevistados, por representar um gasto a menos em sua despesa familiar. Planos de saúde, nesse sentido, deixam a desejar.

A comparação dos entrevistados entre serviços privados e públicos de saúde podem explicar os motivos para esses consumidores de baixa renda exaltarem o acesso a planos de saúde. Por já terem passado por "situações desagradáveis" em clínicas e hospitais públicos, valorizam ainda mais quando são "tratados dignamente" na rede privada e percebem que seus problemas de saúde são sanados adequadamente. Mesmo se o serviço privado de saúde "não for lá essas coisas", e apresente demoras e médicos pouco atenciosos, o imaginário de que o serviço público é pior parece fazer com que o nível de tolerância desses consumidores quanto ao primeiro seja significativo. As diferenças significativas entre os dois tipos de serviços de saúde deixa clara a hierarquização existente dentro do segmento de baixa renda, ajudando a reforçar a máxima de que existem os "pobres" e os "pobres-pobres" (CASTILHOS; ROSSI, 2009). 
Tal discussão sobre os significados associados por consumidores de baixa renda a planos de saúde e o serviço público de saúde dificilmente seria encontrada quando o consumidor em questão é o de alta renda. Essa parece ser uma característica do público entrevistado para a presente pesquisa, pois faz parte de seu cotidiano. Mesmo que, agora, a maioria possua um plano e possa usufruir da rede privada, diversos de seus familiares e amigos "não contam com a mesma sorte". Reconhecem, por isso, que são felizardos, mas entendem que, em função da sua relação com planos de saúde ser frágil, sabem que, algum dia, podem precisar voltar a usar o serviço público e a enfrentar suas más condições.

\section{CONSIDERAÇÕES FINAIS}

O presente trabalho teve como objetivo entender os significados atribuídos por consumidores de baixa renda a planos de saúde. Para isso, foram conduzidas 18 entrevistas em profundidade com consumidores desse estrato social que possuem ou já possuíram planos de saúde. A partir da análise dos dados, é possível chegar a algumas considerações finais.

Por meio de uma perspectiva interpretativista, é possível entender que, para consumidores de baixa renda, planos de saúde apresentam significados de consumo maiores do que somente seus benefícios funcionais. Poder consumir esse serviço promove, por si só, uma sensação de melhora de saúde, e maiores sentimentos de segurança e amparo. Devido aos benefícios simbólicos associados a planos de saúde, consumidores de baixa renda que os utilizam acabam por ser vistos como destacados de seus pares, que, em diversos casos, somente podem recorrer ao serviço público quando incorrem em problemas de saúde. Em parte, essa visão ocorre porque esses consumidores passam a usufruir de serviços de saúde tidos como de qualidade, de um patamar acima daquele que as massas menos favorecidas possuem acesso. Todavia, é possível perceber que existe um desejo de que esse benefício não seja exclusivo, pois poder consumir bons serviços de saúde deveria ser um mínimo para todos. Por trás desse pensamento está a angústia de pensar que a dependência em clínicas e hospitais públicos e todas as suas falhas condições é um fardo indesejado a seus pares mais próximos.

É possível que esse desejo não seja somente pensado em associação a seus pares, pois consumidores de baixa renda compreendem que o consumo de planos de saúde está relacionado à empresa na qual trabalham lhes dar acesso a tal serviço. Caso essa situação não ocorra, a manutenção do plano por conta própria dificilmente é possível, levando esses consumidores a também fazerem parte das massas insatisfeitas que somente possuem o serviço público de saúde para se tratar. Essa frágil condição torna esses consumidores dependentes de seus empregos, pois sabem que a eles é dado o direito de consumir o plano de saúde, mas quem detém sua posse é o empregador. A qualquer momento, portanto, os sentimentos de segurança e amparo podem escorrer por suas mãos.

O maior esclarecimento sobre os significados associados por consumidores de baixa renda a planos de saúde torna mais claro o entendimento de que por meio desse consumo o grupo em questão busca uma posição de maior inclusão na sociedade. Dessa forma, o acesso a clínicas, hospitais e médicos da rede privada permite a esses indivíduos se sentirem cidadãos, algo que dificilmente sentem quando são obrigados a usar da rede pública de saúde. Na verdade, quando se encontram nessa segunda situação, veem o quanto são excluídos socialmente, pois nem o próprio governo, que deveria ser encarregado de lhes proporcionar serviços básicos, olha por eles. 
Nesse processo de se tornar cidadão por meio do consumo de planos de saúde, consumidores de baixa renda passam a ter experiências que Ihes dão mais consciência sobre o que é um serviço de saúde de qualidade supostamente superior àquele oferecido no âmbito público. Isso, por consequência, os torna mais exigentes quanto ao que deve ser um serviço de saúde. Ao perceberem que bom atendimento e infraestrutura são pouco comuns em clínicas e hospitais públicos, passam a ter sentimentos negativos quanto à possibilidade de ele próprio ou qualquer outro consumidor-cidadão precisar se tratar em tais locais. Deixar de ser dependente dos serviços do governo, e passar a ser dependente de empresas que oferecem planos de saúde, parece ser, então, uma escolha fácil para esses consumidores.

A literatura de marketing pouco atenta a esses aspectos sobre consumidores de baixa renda e a sua relação com planos de saúde. A partir do uso da perspectiva de Cultura e Consumo, espera-se ter conseguido contribuir para um conhecimento inicial sobre esse fenômeno ao apontar como tais serviços impactam esse grupo em particular no que diz respeito à manutenção de sua saúde como uma forma de melhorar a sua qualidade de vida. Mais do que um entendimento funcional sobre os seus benefícios, o presente estudo buscou mostrar os ganhos simbólicos que essa parcela da sociedade percebe estar inerentes a tais serviços. Reconhecer esses aspectos simbólicos, tanto quanto aqueles funcionais, associados a planos de saúde, portanto, ajuda a conhecer melhor os motivos por trás da tamanha valorização que consumidores de baixa renda dão a tais serviços, que bem possivelmente é diferente da visão que consumidores mais abastados possuem sobre o mesmo (CHAUVEL, 2000; SANTO; HEMAIS, 2017). Ao reconhecer esse lado menos racional do consumo de planos de saúde por parte de consumidores de baixa renda, a literatura de marketing se torna mais precisa em sua análise sobre esse fenômeno, pois traz à tona discussões que mostram o quão mais complexa é a relação desses indivíduos com o consumo desse serviço, em particular, e até de outros bens e serviços, em geral. Os resultados aqui apresentados são um começo para entender melhor a relação entre consumidores de baixa renda e planos de saúde. Porém, a partir dos achados, é possível perceber implicações importantes para o meio empresarial. Para empresas que oferecem planos de saúde a funcionários, parece ficar claro que esse é um estímulo que deveria ser bastante enfatizado em processos de contratação, especialmente quando o candidato em questão for de classes socioeconômicas de baixa renda.

Para operadoras de planos de saúde, os achados da pesquisa também mostram importantes contribuições. Dado que os entrevistados mostram não diferenciar a operadora do restante da rede de atendimento, cabe a essas empresas saberem gerenciar de maneira criteriosa esse relacionamento. Da mesma forma que é benéfico à operadora ser associada a um bom hospital, seria desastroso à sua imagem ser vinculada a médicos incompetentes. Portanto, educar o consumidor quanto ao papel da operadora e dos demais membros da rede pode ser uma forma de evitar futuras decepções quanto ao serviço.

Embora a presente pesquisa tenha encontrado significados associados a planos de saúde por consumidores de baixa renda, está longe de esgotar o tema. Assim, surgem possibilidades para futuros estudos aprofundarem a discussão levantada aqui. Seria interessante, por exemplo, acompanhar um grupo de consumidores de baixa renda ao longo do tempo, para analisar a relação desses com planos de saúde e se os significados associados ao serviço se mantêm ao longo do tempo. Nenhum dos entrevistados da pesquisa parece ter tido problemas com suas operadoras, situação essa que pode mudar os simbolismos associados a tais serviços. Além disso, seria importante analisar se significados podem mudar a depender do plano que o consumidor possui, buscando entender se planos mais baratos, que oferecem menos serviços, possuem simbolismos similares ou distintos a planos mais caros, com maior variedade de serviços. 


\section{REFERÊNCIAS}

AGÊNCIA NACIONAL DE SAÚDE SUPLEMENTAR Dados da Saúde Suplementar. $2017 . \quad$ Disponível em: http://www.ans.gov.br/aans/noticias-ans/numeros-do-setor/3722-dados-do-setor. Acesso em 30 jun., 2017.

ALCOFORADO, F. A escolha do plano de saúde pelo consumidor: uma visão antropológica. In: MIGUELES, C. (Org.). Antropologia do Consumo: casos brasileiros. Rio de Janeiro: FGV, 2007.

ANFARA, V.; BROWN, K.; MANGIONE, T. Qualitative analysis on stage: making the research process more public. Educational Researcher, v.31, n.7, p.28-38, 2002.

ARNOULD, E. J.; THOMPSON, C. J. Reflections Twenty Years of Research. Journal of Consumer Research, v.31, n.4, p.868-882, 2005.

BARKI, E.; PARENTE, J. Consumer behavior of the base of the pyramid market in Brazil. Greenleaf Publishing, May, p.11-23, 2010.

BARONE, S. Planos de saúde: a dimensão simbólica do contrato. In: MIGUELES, C. (Org.). Antropologia do Consumo: casos brasileiros. Rio de Janeiro: FGV, 2007.

BARROS, C. A "invisibilidade" do mercado de baixa renda nas pesquisas de marketing. In: ENCONTRO DE MARKETING DA ANPAD, 2, 2006, Rio de Janeiro. Anais. Rio de Janeiro: ANPAD, 2006.

BARROS, C.; ROCHA, E. Lógica de consumo em um grupo das camadas populares: uma visão antropológica de significados culturais. In: ROCHA, A.; SILVA, J. (Orgs.) Consumo na base da pirâmide: estudos brasileiros. Rio de Janeiro: Mauad X, 2009. 255p.

BELK, R. Possessions and the Extended Self. Journal of Consumer Research, v.15, n.2, p.139, 1988.

BELK, R.; GER, G.; ASKERGAARD, S. The fire of desire: a multisited inquiry into consumer passion. Journal of Consumer Research, v.30, n.3, p.326-351, 2003.

BUSS, P. Promoção da saúde e qualidade de vida. Ciência e Saúde Coletivas, v.5, n.1, p. 163-177, 2000.

CARSON, D.; GILMORE, A.; PERRY, C.; GRONHAUG, K. Qualitative Marketing Research. London: Sage Publications, 2005. 239p.

CASADO, L.; SATO, K. Classe D agora tem plano de saúde e seguro de vida. Valor. 9 de abril de 2012. Caderno de Finanças Pessoais.

CASOTTI, L.; SUAREZ, M. Dez anos de consumer culture theory: delimitações e aberturas. Revista de Administração de Empresas, v.56, n.3, p.353-359, 2015.

CASOTTI, L.; SUAREZ, M.; DILEZA, R. Consumo de alimentos nas famílias de baixa renda: compartilhando achados, experiências e aprendizados. In: ROCHA, A.; SILVA, J. (Orgs.). Consumo na base da pirâmide: estudos brasileiros. Rio de Janeiro: Mauad, 2009.

CASTILHOS, R. B.; ROSSI, C. A. V. Subindo o morro: consumo, posição social e distinção entre famílias de classes populares. In: ROCHA, A.; SILVA, J. F. (Orgs.). Consumo na base da pirâmide: estudos brasileiros. Rio de Janeiro: Mauad, 2009.

CHAUVEL, M. A. Consumidores Insatisfeitos - uma oportunidade para as empresas. Rio de Janeiro: Mauad, 2000.

CHAUVEL, M.A.; MATTOS, M. Consumidores de baixa renda: uma revisão dos achados de estudos feitos no Brasil. Cadernos Ebape, v.6, n.2, p.1-17, 2008.

CRESWELL, J. W. Projeto de pesquisa - métodos qualitativo, quantitativo e misto. 3. ed. Porto Alegre: Artmed, 2010.

DOUGLAS, M.; ISHERWOOD, B. O mundo dos bens: para uma antropologia do consumo. Rio de Janeiro: UFRJ, 2009.

ELIAS, J. Carta Capital - Quem paga a conta pela crise econômica. 2016. Disponível em: <http://www.cartacapital.com.br/revista/894/quem-paga-a-conta-pela-crise-economica>. Acesso em: 12 maio, 2017.

GUEST, G.; BUNCE, A.; JOHNSON, L. How many interviews are enough?: an experiment with data saturation and variability. Field Methods, v.18, n.1, p.59-82, 2006.

GUMMESSON, E. Qualitative research in marketing - road-map for a wilderness of complexity and unpredictability. European Journal of Marketing, v.39, n.3/4, p.309-327, 2005.

KOZINETS, R. V. Utopian enterprise: Articulating the meanings of Star Trek's culture of consumption. Journal of Consumer Research, v.28, n.1, p.67-88, 2001.

LEVRINI, G.; POLETTI, L. A experiência do estigma dos consumidores de baixa renda no encontro de serviços. Revista de Administração da Universidade Federal de Santa Maria, v.9, n.2, p.210-227, 2016.

LIMA-COSTA, M.F. Estilos de vida e uso de serviços preventivos de saúde entre adultos filiados ou não a plano privado de saúde (inquérito de saúde de Belo Horizonte). Ciência e Saúde Coletivas, v.9, n.4, p.857-864, 2004.

LIVRAMENTO, M. N.; HOR-MEYLL, L. F.; PESSÔA, L. A. G. D. P. Valores que motivam mulheres de baixa renda a comprar produtos de beleza. RAM - Revista de Administração Mackenzie, v. 14, n. 1, p. 44-74, 2013.

MATTOSO, C.; ROCHA, A. Building, losing, and reconstructing social identities: an investigation into the symbolic use of credit by poor consumers in Brazil. Latin America Business Review, v.9, p.227-256, 2008.

MACLAREN, P.; BROWN, S. The center cannot hold: consuming the utopian marketplace. Journal of Consumer Research, v.32, n.2, p.311-323, 2005. 
MCCRACKEN, G. Cultura e Consumo: novas abordagens ao caráter simbólico dos bens e das atividades de consumo. Rio de Janeiro: Mauad, 2003.

MINAYO, M.C.; HARTZ, Z.; BUSS, P. Qualidade de vida e saúde: um debate necessário. Ciência e Saúde Coletivas, v.5, n.1, p.7-18, 2000.

MOREL, A.; MACEDO, S.; SETTE, R.; REZENDE, D. Simbolismo e extensão do self no consumo de produtos de beleza. Revista Pretexto, v.17, n.1, p.11-28, 2016.

NERI, M. A Nova Classe Média: O lado brilhante da base da pirâmide. Rio de Janeiro: Saraiva, 2011.

NOGAMI, V. K. D. C.; VIEIRA, F. G. D.; MEDEIROS, J. Reflexões acadêmicas e de mercado para o Marketing na base da pirâmide. Revista de Negócios, v.17, n.4, p.55-73, 2012.

PINTO, M. As experiências de consumo de eletrônicos de consumidores de baixa renda no Brasil. Revista Brasileira de Marketing, v.12, n.1, p.166-195, 2013.

PONCHIO, M.; ARANHA, F. Necessidades, vontades e desejos: a influência do materialismo sobre a dívida de consumo dos paulistanos de baixa renda. In: ROCHA, A.; SILVA, J. (Orgs.). Consumo na base da pirâmide: estudos brasileiros. Rio de Janeiro: Mauad, 2009.

PRAHALAD, C. K.; HAMMOND, A. Serving the world's poor profitably. Harvard Business Review, v.80, n.9, p.4-11, 2002.

PRAHALAD, C. K.; HART, S. L. The Fortune at the Bottom of the Pyramid. Strategy+Business Magazine, n.26, p.273, 2002.

RAMALHO, R.; AYROSA, E. Subcultura Tuning: a identidade estendida na personalização de automóveis. Revista de Ciências da Administração, v.11, n.24, p.169-194, 2009.

ROCHA, A. R.; ROCHA, A. Consumidores da base da pirâmide e as restrições ao lazer. Revista Pensamento Contemporâneo em Administração, v. 6, n. 2, p. 1-13, 2012.

ROCHA. A.; SILVA, J. F.; Consumo na base da pirâmide: um desafio empresarial - considerações finais. In: ROCHA, A.; SILVA, J. (Orgs.) Consumo na base da pirâmide - estudos brasileiros. Rio de Janeiro: Mauad X, 2009.

ROCHA, E. Invisibilidade e revelação: camadas populares, cultura e práticas de consumo: apresentação. In: ROCHA, A.; SILVA, J. (Org) Consumo na base da pirâmide: estudos brasileiros. Rio de Janeiro: Mauad X, 2009a, 255p.

RUBIN, H.; RUBIN, I. Qualitative interviewing: the art of hearing data (2.ed). Thousand Oaks: Sage, 2005.

SANTO, P.; HEMAIS, M. Discriminação contra consumidores de baixa renda. Revista Pretexto, v.18, n.1, p.64-79, 2017.

SOUZA, M. A. PIERUCCINI; KACHUBA, D. Novas interpretações para o consumo de massa no Brasil: uma análise sob a ótica dos planos econômicos. Percurso Acadêmico, v.5, n.10, p. 329-352, 2015.

SPIGGLE, S. Analysis and interpretation of qualitative data in consumer research. Journal of Consumer Research, v.21, n.3, p.491-503, 1994.

YACCOUB, H. A chamada "nova classe média": Cultura material, inclusão e distinção social. Horizontes Antropológicos, v.17, n.36, p.197-231, 2011. 